Discussion Paper No. 02-70

The Changing Life Cycle Pattern in Female Employment:

A Comparison of Germany and the UK

Bernd Fitzenberger and Gaby Wunderlich

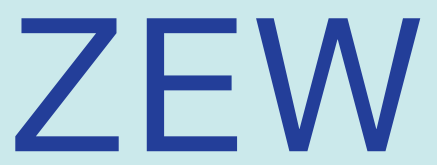

Zentrum für Europäische Wirtschaftsforschung GmbH

Centre for European

Economic Research 
Discussion Paper No. 02-70

\title{
The Changing Life Cycle Pattern in Female Employment: A Comparison of Germany and the UK
}

\author{
Bernd Fitzenberger and Gaby Wunderlich
}

Download this ZEW Discussion Paper from our ftp server:

ftp://ftp.zew.de/pub/zew-docs/dp/dp0270.pdf

Die Discussion Papers dienen einer möglichst schnellen Verbreitung von neueren Forschungsarbeiten des ZEW. Die Beiträge liegen in alleiniger Verantwortung der Autoren und stellen nicht notwendigerweise die Meinung des ZEW dar.

Discussion Papers are intended to make results of ZEW research promptly available to other economists in order to encourage discussion and suggestions for revisions. The authors are solely responsible for the contents which do not necessarily represent the opinion of the ZEW. 


\section{Non-technical Summary}

Rising female employment rates are a general trend in the industrialized countries throughout the second half of the last century. Another stylized fact is that women's employment patterns are distinct from those of men. For example, women are more often part-time employed and interrupt their careers more frequently. Aggregate employment rates are therefore not very informative regarding the measurement of female labor force participation.

Aggregate economic activity rates for all women aged 16-60 started to rise from 50 per cent in the late 1970s to 60 per cent in the 1990s in West Germany - measures for the UK are roughly 10 percentage points higher. These numbers represent a very simplified picture of female employment trends, because they summarize a variety of developments. The composition of the female workforce by qualification and age has changed very much. Also, part time rates as shares of total employment have changed in both countries.

The paper analyzes whether there is in fact just a "myth of rising female employment" for West Germany and the UK in that the head count approach ignores the real changes having occurred during the last decades. Our intention is to analyze actual trends and changes in economic activity rates taking the aforementioned compositional effects into consideration. We do this by distinguishing several groups of differently qualified fulltime and part-time employed females. A descriptive econometric model is used which takes the effects of age, time, and cohort membership simultaneously into account. This has advantages compared to the usual cross tabulation analysis which can not identify the three effects simultaneously. The empirical analysis is based on the German Micro Census and the British General Household Survey.

The empirical results show many similarities but also some remarkable differences between West Germany and the UK regarding trends in full- and part-time work across skill groups. Over the life-cycle, full-time employment rates decrease strongly and part-time employment rates increase strongly in both countries. The time trends differ considerably and the small increase in the full-time employment rates both in Germany and the UK is the result of various strong counteracting effects. The strong aggregate increase in part-time rates is mainly due to the demographic aging effect together with increasing life-cycle profiles and to skill upgrading in both countries. Taken together our results show strong differences across countries and skill groups and there is in fact some evidence of a "myth of rising female employment" since the rise in employment rates is concentrated in part-time employment and, most importantly, it is mainly due to composition effects. 


\title{
The Changing Life Cycle Pattern in Female Employment: A Comparison of Germany and the UK ${ }^{1}$
}

\author{
Bernd Fitzenberger ${ }^{2}$ and Gaby Wunderlich ${ }^{3}$
}

\author{
September 2002
}

\begin{abstract}
It is often noted that employment rates of females have been rising during the last decades. However, in contrast to men, women are often part-time employed and the allocation of working time over the life-cycle is linked to family formation. In addition, employment rates may differ across skill groups and countries due to differences in incentives to work and in labor market attachment. This paper analyzes empirically macroeconomic trends and life-cycle profiles in full-time and part-time employment of different skill groups of women in the UK and West Germany. The analysis is based on large cross-sectional data sets for a time period of 20 years. We find that patterns of part-time and full-time employment are surprisingly different across skill groups and countries. In particular, the life-cycle patterns are such that full-time employment declines and part-time employment increases with age in both countries. Time trends do not change in a monotonous way across skill groups and they differ by country. There is almost no evidence for a positive time trend in part-time employment thus the strong increase in part-time rates in both countries can mainly be attributed to composition effects. Our findings are based on an empirical model taking the effects of time, age, and birth cohort membership simultaneously into account.
\end{abstract}

Acknowledgement: The British data we have used in this paper were made available through the Data Archive at the University of Essex, UK. The German data were made available through ZUMA, Mannheim. The data providers do not bear any responsibility for the analysis presented here. We are grateful to Reinhold Schnabel for help on the German data and Martin Salm for assistance when preparing the British data. All errors are our sole responsibility.

Keywords: Part-time and Full-time Employment, Females, Cohort Analysis

JEL Classification: J16, J2, J71

\footnotetext{
${ }^{1}$ This paper is part of the research project "Holen die Frauen auf? Ein Vergleich von Erwerbsverhalten, Beschäftigung und Verdiensten deutscher und britischer Frauen im Zeitverlauf" at the Centre for European Economic Research (ZEW). We thank the Hans-Boeckler-Stiftung for financial support.

${ }^{2}$ University of Mannheim, ZEW and IFS. Address: University of Mannheim, Department of Economics, 68131 Mannheim, Germany. E-mail: bernd.fitzenberger@vwl.uni-mannheim.de.

${ }^{3}$ Centre for European Economic Research (ZEW), Department of Labour Economics, Human Resources, and Social Policy, 68161 Mannheim, Germany. E-mail: wunderlich@zew.de.
} 


\section{Contents}

1 Introduction $\quad 1$

2 Data 4

2.1 The General Household Survey (GHS) . . . . . . . . . . . . . . . 5

2.2 The German Micro Census . . . . . . . . . . . . . . . . . . . . . . 6

3 Basic Trends in Full- and Part-time Employment $\quad 7$

4 Empirical Model $\quad 9$

$\begin{array}{llr}5 & \text { Results } & 11\end{array}$

6 Conclusions $\quad 15$

$\begin{array}{lr}\text { A Appendix } & 19\end{array}$

A.1 Methodological Details of the Empirical Approach . . . . . . . . . . 19

A.1.1 Characterizing Profiles of Full-time or Part-time Employment Rates .................. . . 19

A.1.2 Testing for Uniform Changes over Time . . . . . . . . . . 20

A.1.3 Implementation of the Tests . . . . . . . . . . . . . . . . . 21

A.1.4 Block Bootstrap Procedure for Inference . . . . . . . . . . . . . 22

A.2 Figures and Tables . . . . . . . . . . . . . . . . . . . . . . 23 


\section{Introduction}

Rising female employment rates are found as a general trend in the industrialized countries throughout the second half of the last century (Altonji and Blank, 1999). Nevertheless, this broad statement requires some qualifications regarding the specific nature of female employment patterns. In contrast to men, women are disproportionately part-time employed and there exist distinctive live-cycle patterns both in the timing and the type of female employment. Therefore aggregate employment rates are not a very informative measure of female labor force participation. According to various contributions in Blossfeld/Hakim (1997), the increase in female participation rates can be attributed mainly to part-time work in most European Countries and the US. Furthermore, only the US has exhibited a steady growth in female employment since the beginning of the century. European countries have experienced increases in female (part-time) employment beginning with the 70s (see Blossfeld/Hakim 1997, for the US see Goldin 1990, Jacobsen 1998).

The UK and West Germany differ in their labor market institutions, national labor market policies, and in various labor market developments as well as in their social and family policy with impact on the labor market. The latter refers in particular to the availability of child care facilities, length of school day, taxation of spouses, and flexibility of working times. The tax systems of the two countries differ in tax units, tax rates, tax brackets and allowances (see Vermeulen et al., 1995). Moreover, the British tax system was reformed in 1990: Prior to 1990 the income taxes were based on the family income - following analogous principles as in the German case. Since then, each spouse in the UK is taxed separately on his or her earned and unearned income (see Stephens/Ward-Batts, 2001). Social security contributions which have to be payed by employers and employees are different in Germany and the UK, but in both countries there exists a contribution free lower earnings limit potentially creating incentives to work part-time (Vermeulen et al., 1995). There are further differences regarding wage bargaining institutions. In Germany, while there is no minimum wage, there is strong industry bargaining with a high degree of compliance with collective bargaining agreements among employers. In contrast, multi-employer national agreements collapsed after 1979 in the UK and union density declined rapidly (Black et al., 1999). This is s supposed to be strongly related to differences in the distributions of income and wages in both countries (Giles et al. 1998). Another difference between the countries, regarding particularly female employment are that activity rates of women are higher and gender specific wage differentials are declining stronger in Great Britain (OECD, 1988).

Aggregate economic activity rates for all women aged 16-60 started to rise from 50 percent in the late 1970s to 60 percent in the 1990s in West Germany. This aggregate number summarizes a wealth of different developments among females. For example, employment rates of young women decreased because of longer schooling whereas married females increased their employment rates extraordinarily (Blossfeld and Rohwer 1997). Comparing the overall economic employment rates of British women aged 16-60 in Burchell et al. (1997) to the respective numbers for Germany (West) in Blossfeld and Rohwer (1997), it is clear that overall employment rates of British females are roughly 10 percentage points (ppoints) higher. Also in the UK, married females increased their 
employment rates remarkably. Part-time employment as a share of total employment has grown in both countries. Between 1973 and 1995 it rose from 16 to 24 percent in the UK, and from 10 to 16 percent in Germany (OECD, 1996). That is, the part-time share in total employment is lower in Germany. The same is true for the share of parttimers within the group of all working women. In 1973, 24 percent of working females have been part-timers in Germany and 39 per cent in Britain. During the following two decades, this share increased rougly by 10 ppoints in Germany and 5 ppoints in Britain (OECD, 1996). The numbers show that part-time employment among females has traditionally been more important in the UK compared to Germany and that the increase in employment rates can be attributed mostly to an increase in part-time employment rates in both countries. The latter effect is stronger for Germany such that the part-time gap between the two countries has actually been declining.

In addition to distinguish between full-time and part-time employment, it is also important to analyze the timing of employment states during the life-cycle of female workers. Increases in formal education levels, changes in fertility rates and in the timing of birth, and changing policies regarding employment of women with children are related to changes in the life-cycle employment patterns over time and across birth cohorts.

This paper analyzes whether there is in fact just a "myth of rising female employment" (Hakim, 1993) for West Germany and the UK. According to Hakim's hypothesis it is not the case that male and female activity rates are converging and will soon be the same. The background of her statement is that the head count approach underreports gender differentials in workforce participation and also ignores the real changes which have occurred during the last decades (Hakim 1993: 108f.). The argument is quite plausible but Hakim does not distinguish between, for example, age groups or skill groups and does not take into account demographic change, change of schooling duration etc. To analyze actual changes in workforce participation it is necessary to take such compositional effects into consideration. According to the General Household Survey for the UK and the Micro Census data for West Germany (see section 2), the skill distribution has changed over time both in the group of female full-time and parttime employees aged 20 to 60 years with valid skill information. Although skill levels are far from being perfectly comparable across the two countries, we find strong skill upgrading among full-time and part-time employees in both countries (see figure 1 in the appendix). The trends of skill upgrading are nearly linear over time in Great Britain and Germany. The shares of medium and high skilled employees increased and the share of the low skilled decreased. In the UK, the average skill level seems to be lower for part-time employees than for full-time employees. For Germany, we do not find such a difference between skill levels by employment status.

In this paper, we distinguish full-time and part-time employment and identify aggregate macroeconomic trends and life-cycle profiles for both employment groups. Our descriptive econometric model takes the effects of age, time, and cohort membership simultaneously into account and goes beyond the usual cross tabulation analysis. We investigate moreover, if aggregate employment trends differ by skill level which is interesting in the light of the hypothesis of "skill biased technological change" and its impact on the demand for heterogeneous labor (see Blau/Kahn, 1997 and Berman/Bound/Machin, 1998). 
In the subsequent sections we often refer to "life-cycle employment patterns" which describe how labor market activity rates of women vary over age. These patterns are, to some extent, due to family responsibilities which are still carried out for the most part by women. A focus of our analysis is the question, whether these patterns have changed over time or cohort succession. At an international perspective, one can observe various age related employment patterns (see OECD 1988: 49, 134; Rubery et al. 1999: 84) resulting from institutional differences such as the generosity of family leave or the availability of child care facilities. When describing these patterns the literature usually does not distinguish between full- and part-time employment. Thus, drawing general conclusions about changing female employment patterns is difficult in this case because working hours typically vary substantially across age while the employment rate changes only little.

The first age pattern discussed in the literature, which is denoted as the male pattern, is inverted U-shaped. Employment rates rise strongly up to an age of around 30 years, stay constant, and start falling strongly at around 55 years. If such a pattern is observed for females the institutional setup is such that child raising and employment are compatible which could, to a smaller or larger extent, be due to part-time employment. Splitting the group of female employees by working time should allow to interpret aggregate employment trends in a better way. Moreover, because of family related reasons, the probability of working part-time increases from the start of a women's career until age 30-40 and decreases thereafter, aggregate part-time employment patterns should be inverted U-shaped.

The second, M-shaped pattern, is often denoted as the "returner pattern". Such a pattern exhibits a valley during the child bearing/raising phase of females because the presence of young children is a major barrier to participation (OECD 1988: 49). After an interruption due to the family phase, women return to the labor force. Again, most studies at the aggregate level make no distinction between full- and part-time employment. Therefore, the pattern should look differently when we distinguish by employment status. As an extreme case one could imagine that women completely return to part-time employment after the family phase or stay in part-time employment if they do not completely stop working. This would transform the M-shaped pattern into a left hand peak curve or "permanent labor market exit curve" - in this case, exit from full-time employment into part-time or non employment. Usually, the permanent exit pattern is observed in societies where many women permanently withdraw from the labor force after marriage and/or children (OECD 1988: 49).

We expect that life-cycle employment profiles differ strongly by employment status. It is very likely that full-time employment is substituted by part-time employment once children are to be cared for. It depends upon institutional settings whether full-time employment is substituted by part-time or by nonemployment. This might also have consequences for the re-entry into the labor market after the family phase.

The estimation of age patterns requires some further explanations since the discussion so far did not distinguish between time and cohort effects. The literature typically analyzes cross-sectional employment patterns across persons of different age for a given point in time effectively also comparing employment across different birth cohorts. Even though there exists a perfect linear relationship between age, cohort, and time, 
we test in our analysis whether the effects of age, cohort, and time on employment rates are separable. If this is the case, then a life-cycle (or age) profile can be identified which is common to all cohorts we observe. Moreover, the relationship between labor market activity rates on the one hand and the terms of age, time, and cohort membership on the other hand is additive in our model. That is, the life-cycle profile we identify, and which has the same shape for all cohorts in the data, might nevertheless change its location over time. For example, we could possibly identify a permanent exit pattern, common to all cohorts in the data, and a significant positive time trend, the result being a change of the location (but not the shape) of the life-cycle profile over time. Then, an individual cohort might experience increasing employment rates over time even though the life-cycle profile by itself would indicate a decline of employment rates at this age. This shows the importance of distinguishing between the shape and location of the life-cycle profile.

Simplifying matters a bit, one could summarize the various possible movements of the profiles as follows: Vertical parallel shifts of the age related cross section profile indicate intra cohort employment changes over time whereas a change of shape of the cross section profile reflects inter cohort differences in their employment life-cycle. For younger cohorts of women participation per se as well as timing and duration of job interruptions may have changed gradually. If cohorts do not behave differently, which one might assume to be the case for men (except for the very young and the old), then aggregate age related patterns in employment rates are the same across cross-sections.

Investigating differences in employment rates of synthetic cohorts, the processes described above can be analyzed (see for example OECD 1988: chapter 1 and 5, Shaw 1994: 351, Jacobsen 1998: 114) based on data consisting of a sequence of representative cross-sections without the need for panel data (panel data sets are not available for the long time period investigated here and it would also be doubtful that representativeness is kept over such a long time period). The approach of synthetic cohorts in aggregate data examines labor force behavior of demographic groups as they age. Distinguishing cohorts matters a lot, especially for married women since: "... cohorts acquire varying amounts of education, have different numbers of children, accumulate different types of labor market experience, and mature in different social climates" (Goldin 1990: 138).

The remainder of the paper is organized as follows. Section 2 describes the data. Then, we discuss some basic trends in section 3. Section 4 develops the empirical model to distinguish cohort, age, and time effects. The empirical results are presented and discussed in section 5. Section 6 concludes. The appendix contains details of the empirical model, tables, and figures.

\section{Data}

It is difficult to find national survey data for different countries which are comparable from the start. In contrast, international surveys are in most cases designed in the same way across the countries they include, but their sample sizes are fairly low and the surveys do not involve very long time periods. Besides this, general problems remain with respect to the comparability of educational systems and labor market regimes. 
Regarding the two countries investigated in this study, rather strong differences in educational systems exist and the distribution of working hours by employment status differs across the countries as well. These unavoidable limitations should be kept in mind.

Our analysis is based on the British General Household Survey for the years 1975 to 1995 and the German Micro Census for various years (not all) between 1976 and 1995. The reasons for the latter will be discussed in more detail in section 2.2. The subsequent analysis of the GHS builds on individual data. In contrast, the analysis of the Micro Census uses grouped data. Since the data are grouped by the regressors of our linear econometric model, the use of grouped data does not involve any loss of information.

\subsection{The General Household Survey (GHS)}

The General Household Survey (GHS) was started in 1971. It is conducted by the Office of Population Censuses and Surveys based on a random sample of the population living in private (post-coded) households in the U.K. and it covers around 10,000 households each year. Between 1971 and 1996/97 interviews were carried out annually. Each household member of age 16 and above is interviewed. For this study, we use the repeated annual cross-sections from 1975 to 1995/96. The questionnaire includes a wide variety of information on housing, demographics, household structure, labor market status, and sources of income.

The employment status variable in the GHS refers to the status in the last week. A women considered as employed may be either self- or dependently employed. We use the usual weekly working hours reported in the GHS to distinguish between full-time and part-time employment. We do this because the question about usual working hours is unaltered throughout the whole period and we think that usual hours represent a medium-term average of working time. Full-time employment is defined as working more than 35 hours a week. The third category in addition to full-time and part-time employment comprises non-employment as well as unemployment. ${ }^{1}$ For the British data we define two dependent dummy variables: State full-time employed versus all other labor market states and state part-time employed versus all other labor market states.

We use data of individuals between age 20 (age 25 for high skilled individuals) and 60 for whom valid information on educational attainment, age, gender, usual working hours, and employment is available. All other observations are dropped. The age interval for high skilled persons is reduced because these individuals usually finish full-time education in their mid twenties. The data include all nationalities. We have dropped the Scottish Supplementary Sample because it involves only a short interview with one responsible adult in the household and only a limited number of (mostly household) variables is contained in it.

\footnotetext{
${ }^{1}$ For the German data, the dependent variable is computed as a continuous full-time (part-time) employment rate within an age-year cell for each skill group.
} 
The GHS provides detailed information about each respondent's educational background. Information on the highest educational qualification of each person is available for the period 1975 to 1982. From 1983 onwards, the GHS contains a list of all qualifications each individual has obtained. The questions about obtained qualifications changed slightly in 1988 and again in 1994. From this information we extracted the highest qualification of each person. However, the skill variable exhibits two structural breaks in 1983 and 1994 which results in an increase of missing answers between the two years. There is also a change in the questionnaire for 1988, but this is not visible in the data. We split the employment status groups by skill level into

(U) low skilled individuals who report to have no or an "other" qualification,

(H) high skilled individuals with qualifications above A-level, and

(M) medium skilled individuals who constitute the remaining category.

\subsection{The German Micro Census}

Since 1957, the Federal Statistical Office in West Germany has conducted an annual population survey called the Micro Census ("Mikrozensus"). These data are the main source of official population and labor market statistics in Germany. The surveys are one percent random samples of the residential population in Germany, stratified by some regional variables (state, size of city or county, etc.). After the reunification of Germany, the East German population has been added. The primary sampling units are households. All household members age 16 and older are personally interviewed. Before German unification, the sample size was approximately 250,000 households and 600,000 persons. The questionnaire is regulated by federal law and includes information on demographics, household structure, labor market status, and sources of income. Unfortunately, access to the raw individual data is limited because of restrictive data protection regulations.

However, we could use the subsamples of the Micro Census at the ZUMA Mannheim which contain a limited - and for our purpose sufficient - collection of variables for several survey years $(1976,1980,1982,1985,1987,1989,1991,1993,1995)$. The size of the subsamples ranges from $70 \%$ to $98 \%$ of the original samples. ${ }^{2}$ We had to restrict the sample period due to a lack of consistent information on the skill level in the older censuses. Our working samples cover all West German residents in private homes (excluding institutionalized population). This also includes all nationalities living in Germany. For obvious reasons, we have to exclude the East German population from our analysis for such a long time period.

The employment status variable in the Micro Census is defined according to the ILOStandard. A person is considered employed if he or she worked for pay (either selfor dependently employed). Full-time employment is defined as usually working more than 35 hours per week. A worker is considered unemployed if he or she did not work and was actively searching for a job. The remaining category of non participating

\footnotetext{
${ }^{2}$ The proportion is $98 \%$ for $1976,1980,1982,1985$, and $70 \%$ for $1987,1989,1991,1993,199570 \%$.
} 
individuals applies if neither of the former two conditions is satisfied. In contrast to the British data, we group the data and construct skill and age specific full-time and part-time employment rates for various years. We define:

UN: number of unemployed women,

FEMP: number of full-time employed women,

PEMP: number of part-time employed women, and

NP: number of non-participating women.

The size of an age-skill group (population) in year $t$ is the sum POP $=$ FEMP + PEMP $+\mathrm{UN}+\mathrm{NP}$. The full (part) -time employment rate within an age-skill group in year $t$ is the ratio FEMP/POP (PEMP/POP). We distinguish three skill levels, which are derived from the question about the highest formal qualification in the Micro Census:

Low skill (U): no vocational training degree,

Medium skill (M): vocational training, i.e. apprenticeship, period of practical instructions or training, master certificate or technical expert, and

High skill $(\mathrm{H})$ : $\quad$ university or technical college degree.

Item nonresponse in the skill variable is quite important and may have two reasons. First, many persons have not yet finished their education. This is why nonresponse is decreasing with age. Second, in some years the answer to this question has been voluntary and some persons refused to answer. For those years, we corrected the employment and participation rates using also information from the years when the question was compulsory (see Fitzenberger/Schnabel/Wunderlich (2001), appendix A, for a description of the method).

Note that of all skill groups, the low skilled are the most comparable group across the two countries. High and medium qualifications are rather difficult to compare because there are fundamental differences between the German and the British educational system. In Britain there is only a weak tradition of formalized apprenticeships. In Germany, this tradition is very old and extraordinarily persistent. As a consequence, the medium skill category in our German data consists mainly of individuals who have an apprenticeship.

\section{Basic Trends in Full- and Part-time Employment}

In this section, we describe how cross-section employment profiles across age have changed over time in West Germany and the UK. We distinguish full-time and parttime employment and three skill levels (see figures 2 and 3 in the appendix). The figures for Germany comprise all cross sections (waves) available for our empirical analysis. For clarity, we show only 8 of the available 21 cross sections for the UK. The key (legend) for the several years is contained in the graphs for low skilled in the upper part of figure 2 and 3. To get an intuition of how time and cohort effects could become visible in these graphs, imagine that a change over time which is common to all cohorts in the labor market should shift the profiles in a parallel fashion up or down, whereas 
cohort effects should turn, compress, or stretch the successive cross section profiles unevenly across the age range. The reason for such a nonuniform effect is that cohort effects depict (labor market) shocks which affect single cohorts (or groups of successive cohorts, e.g. "generations"). A useful example of a cohort effect is the exceptional labor market history of the female war generation.

Figure 2 and 3 show that first, in general, the shapes of full-time and part-time employment profiles are different, second, differences in shapes and levels of part-time as well as full-time profiles are observable across the countries, and third, changes over time (and maybe cohorts) differ across skill groups and countries. The average level of the full-time rate is higher in Germany. The opposite is true for part-time employment. All skill groups follow this pattern. The shapes of German full-time profiles of all skill levels are more distinct because they start at a much higher level. British full-time profiles are flatter.

For Germany, the cross-sections in full-time employment do not exhibit clear parallel shifts over time (see figure 2). If anything, the cross sections have rather turned around a bit clockwise, especially for low and medium skilled females. In 1976, full-time rates of younger age groups have been higher and in older age groups they have been lower compared to the 90's. This is similar to British full-time employed females of low and medium skill level. The cross section profiles of medium and low skilled British females seem to exhibit a stronger tendency in the late thirties and early fourties to return to pre-family phase levels than the profiles of German females with corresponding skill level. The changes in successive cross sections of high skilled German full-time employed women appear rather noisy and there is no clear parallel shift. In contrast, British high skilled females across all age groups exhibit a clear and strong parallel shift to a higher level of full-time employment.

There are pronounced differences in part-time profiles between Germany and the UK (see figure 3). Generally speaking, the part-time profiles of German women are much flatter than the part-time profiles of British women. This is the case for all skill levels. Part-time work at labor market entry is not very common in Germany. The part-time rate amounts to less than 10 percent for low and medium skilled women at entry age 20 and to about 15 per cent for high skilled at entry age 25. These entry levels are constant over time. In contrast, part-time rates at labor market entry of British women are much higher for all skill levels and there is more variance in entry part-time rates observed over time. These differences in levels continue throughout the whole age range and for all skill groups.

For German part-time profiles, cohort effects are clearly visible which is not the case for the UK. We observe for the high, the medium, and (to a minor extent also) for the low skilled a part-time rate for the younger age groups which is nearly constant over time. However, beyond age 30 at the latest, an enormous increase of part-time rates is visible, which is persistent until the end of the age range. This effect is particularly strong for medium and high skilled females in Germany. For British females no clear cut pattern emerges.

To investigate the issues discussed so far more precisely, the next section develops a formal econometric model which intends to separate as much as possible the effects of 
age, time, and birth cohort membership on full- and part-time employment rates.

\section{Empirical Model}

We investigate the full-time employment rates and the part-time employment rates over the years 1975 (for the UK and 1976 for Germany) to 1995 for different cohorts stratified by skill levels. We do this for two countries, the UK and West Germany. A cohort is defined by the year of birth. We use the framework that was first developed in MaCurdy and Mroz (1995) to analyze wage trends in the United States. ${ }^{3}$ This section outlines the basic empirical approach. Further methodological details can be found in the appendix.

Based on longitudinal data for Germany and the UK, we would like to separate the patterns of full-time and part-time employment into age, cohort, and time effects. The age effect describes how the labor market behavior of a given cohort changes as the cohort ages. The time effect describes how macroeconomic shocks shift the labor market outcomes for a given cohort. Cohort effects summarize the difference between cohorts. Of course, it is well known that the three effects cannot be separately identified. More specifically, the linear effects of time, cohort, and age are not separately identified without further prior assumptions. This is due to the fundamental identity that links birth year c, age a, and calendar time $\mathrm{t}$

$$
t=c+\alpha
$$

In the following, we model the employment rate $E R$ (this can denote the full-time employment or the part-time employment rate) for a cohort $c$ at age $\alpha$ as

$$
E R(c, \alpha)=g(c, \alpha)+u
$$

where $g(c, \alpha)$ describes the systematic life-cycle employment patterns for different cohorts and $u$ is a residual component. $E R$ can alternatively be represented as a function of $\alpha$ and $t$ (or even as a function of $c$ and $t$ ):

$$
g(c, \alpha) \equiv g(t-\alpha, \alpha) \equiv f(t, \alpha)
$$

where $f(t, \alpha)$ specifies the cross-sectional age profile at a given $t$. Our empirical analysis focuses on a polynomial representation for $g(c, \alpha)$, which is additively separable in cohort, time, and age effects

\footnotetext{
${ }^{3}$ Among others, it has also been applied in Fitzenberger and Wunderlich (2000, 2001) and Fitzenberger, Hujer, MaCurdy, and Schnabel (2001) in the context of estimating wage equations. Fitzenberger, Schnabel, and Wunderlich (2001) use this framework in the context of labor market participation and employment rates of men and women in West Germany but the analysis there does not distinguish between full-time and part-time employment.
} 


$$
g(c, \alpha)=G+K(c)+A(\alpha)+B(c+\alpha)
$$

where $A(\alpha)$ and $B(c+\alpha) \equiv B(t)$ are polynomials in $\alpha$ and $t$, respectively. Note that in contrast to the linear effects, coefficients on the second, third, etc., powers in $c, \alpha$, and $t$, are identified.

The British sample starts in 1975 and the German in 1976. For the low and medium skilled, we model employment rates for the age range from 20 to 60 years, and for the high skilled from 25 to 60 years. The lower end of this age range is denoted as the labor market entry age and the specification of the cohort effect $K(c)$ differs between those cohorts who in the first sample year 1975/76 were younger than their labor market entry age and those cohorts who already then were older than their labor market entry age: ${ }^{4}$

$$
K(c)=K_{b 2} \cdot c_{b}^{2}+K_{b 3} \cdot c_{b}^{3}+K_{a 2} \cdot c_{a}^{2}
$$

where $c_{a}=0$ and $c_{b}=c$ are for cohorts who were older than their labor market entry age in the first sample year as well as $c_{a}=c$ and $c_{b}=0$ for cohorts who were younger then. We make this distinction since we do not observe labor market entry for older cohorts.

The choice of polynomials is justified since the analysis does not intend to forecast $E R$ outside of the observed sample. In the empirical analysis, we actually center the variable $\alpha$ around the labor market entry age and the variable $t$ around the first sample year. Thus, cohort $c=0$ is the cohort who is at its labor market entry age in the first sample year.

Equation (4) allows for linear terms in $\alpha$ and $t$ but not in $c$. It is clear that, formally, the linear terms are not identified, i.e. the coefficient on $\alpha$ estimates $(A 1-K 1)$ and the coefficient on $t$ identifies $(B 1+K 1)$, where $A 1, B 1$, and $K 1$ are the unknown coefficients of the linear terms in $\alpha, t$, and $c$, respectively. As an identifying assumption, the linear cohort effect $K 1$ is set to zero. This assumption is motivated by equation (4) - see also equation (10) in the appendix - which for a given cohort allows for a separation of changes over time into a pure age and a pure time effect; both are common to all cohorts in the labor market. In light of this condition, setting the linear cohort term to zero is quite natural based on the following argument. If $K(c)=0$, i.e. only a linear cohort term exists, then the entire cross-section profile $f(\alpha, t)$ exhibits purely parallel shifts over time, a situation, one would not naturally characterize by "cohort effects".

Note that the sum of two effects can be identified without additional assumptions. For instance, the sum of age and time effects is identified and yields the longitudinal profile (cohort profile) $A(\alpha)+B(t)$ for each cohort as the change over time and age relative to the cohort specific level $K(c)$. The shape of these longitudinal profiles differs between

\footnotetext{
${ }^{4}$ E.g. for low- and medium skilled British females, $K(c)$ differs between those cohorts who in 1975 were older than 20 years (i.e. who were born before 1955) and those cohorts who in 1975 were at most 20 years old (i.e. who were born in 1955 or after).
} 
cohorts since each cohort experiences the time (macroeconomic) effect at a different point of the life-cycle.

An important issue is that of separability of the three effects as assumed in equation (4). It is not clear from the outset that the labor market outcomes can be represented by such an additive function. We denote this restriction as the hypothesis of a uniform insider trend $\mathbf{H}_{\mathbf{U I}}$ since specification (4) implies that the cohort profiles depend only upon age and time, relative to the cohort specific $K(c)$, defining the level at the entry into the labor market. This hypothesis can be tested without further identifying restrictions. We use specific interaction terms of $\alpha$ and $c$ for this test (see appendix). In testing the separability restrictions, it is important to use robust estimators for the variance-covariance matrix of the parameters. To this end, we use a block bootstrap procedure that controls for a fairly general pattern of correlation in the error term (see appendix).

Only if the hypothesis of separability cannot be rejected, is it justified to speak of age, cohort, and time effects as being separate effects - conditional on our identifying assumption for the linear terms. Otherwise, the "age" effects depend also on cohort and calendar year and so on. A stronger restriction on the specification $g(c, \alpha)$ would be $K(c)=0$. We denote this as uniform growth hypothesis $\mathbf{H}_{\mathbf{U}}$ since under this hypothesis no level differences between cohorts exists. This hypothesis is tested separately for the cohorts born before 1951 and those born afterwards.

In the empirical analysis, we also use orthogonalized as dummies in order to model cyclical movements of employment around its trend as captured by $B(t)$ (see tables 1 and 2 in the appendix). The orthogonalization of the year dummies implies that the estimate for $B(t)$ is not affected by their presence. We start the estimation with the most general formulation of the model, including interaction terms of age, time, and cohort. We then search for the most parsimonious specification that is not rejected by the data. This yields our preferred specification which the discussion of the results is based upon.

\section{Results}

In this section, we present and discuss our findings mainly using graphical illustrations. Tables and figures referred to can be found in the appendix. There are some interesting differences across the countries but also many similarities. We start by describing the macroeconomic time trends for the different employment status groups in both countries, then we discuss differences and similarities of German and British life-cycle profiles of female full-time and part-time employment rates and we finish by describing which cohort effects are observed in the data. We can discuss the effects of the three components time, age, and cohort separately, because the separability hypothesis is never rejected. The additive relationship between labor market activity rates and the three components fits the data well. We have investigated this further by comparing predicted and observed cross sections of full-time and part-time rates (these fitted profiles are available upon request). The final estimation results for both countries and employment states are given in table 1 and 2 in the appendix. Note that the time 
trend is specified linearly for West Germany because we have only 9 cross section years in the data. In contrast, the time trend for Britain is specified as a polynomial of fifth order. Nevertheless, the linear specification is probably a good approximation for the macroeconomic trend (see figures 4 and 5) in the British case.

The most striking finding is the rise in full-time employment rates over time for high skilled British women (see figure 4). Apart from composition effects, the overall increase in employment rates of British women can only be attributed to the increasing fulltime employment rates of high skilled women who expanded their full-time employment rate by 35 percentage points (ppoints) between 1975 and 1995. In addition, the pool of high skilled females increased as well. A possible explanation for this finding is that relative demand for high skilled females might have risen. This result is in line with a strong wage growth for high skilled full-time employed women in the UK (see our companion paper on the wage structure in the UK Fitzenberger/Wunderlich, 2001). Their cumulated growth rate of log real wages between 1975 and 1995 lies between 45 and 60 percent, depending on the quantile of the entire wage distribution. In contrast, medium and low skilled women do not exhibit any significant time trend in full-time employment and their wages do not exhibit such a remarkable increase (see again Fitzenberger/Wunderlich, 2001). There are some ups and downs in full-time rates which are controlled for by the year dummies. Overall, these findings are consistent with the widely accepted hypothesis that the relative demand for high skilled labor has increased over time (Berman et al., 1998).

There is some indication, that the growth of high skilled full-time employment in Britain has overcompensated a fall in part-time employment of this skill group. Figure 5 shows that part-time employment of high skilled females decreased by roughly 10 ppoints during the observation period despite the overall increase in employment rates among high skilled. This finding makes clear that the two working time regimes should be investigated separately. We find a decreasing part-time employment rate for the low skilled females as well. Medium skilled females exhibit neither a significant time trend in full- nor in part-time employment; nothing changed over time for this skill group. Full-time employment rates for low skilled females are constant over time but their part-time rates decreased by 5 ppoints. Because the absolute number of low skilled females decreased over time as well as their (part-time) employment rate, there might be a decrease in labor demand for this group. It is interesting to relate these findings to the results on wages in Fitzenberger/Wunderlich (2001) where we find, that only full-time employed females, and in particular the high skilled have been able to reduce the gender wage gap to any considerable extent, while part-time employed women do not experience any positive change over time.

For Germany the findings are quite different. Full-time and part-time employment rates of high skilled females are constant over time. It is also the case for Germany that educational attainment expanded strongly during the observation period. There are far more high skilled females nowadays than 25 years ago. But because neither the full-time nor the part-time employment rate has risen over time, we conclude that employment for high skilled females was growing proportionately to the growth of this group. The possible explanation of saturated labor demand is in line with the findings in our companion paper on the German Wage structure (Fitzenberger/Wunderlich 2000). There, we find that wage growth of high skilled full-time employed women 
does not differ in an important way from wage growth of medium skilled full-time employed females. For medium skilled women, we observe a significant positive time trend in full-time employment but no trend in part-time employment. The increase in full-time employment amounts to 10 ppoints between 1976 and 1995. Therefore, relative employment of medium skilled females was rising over time even though the size of the group was growing as well. In contrast to the positive employment trends for medium and high skilled females, both the number of low skilled females shrunk exceptionally and within this group fewer females were employed over time. This is only to some extent offset by gains in part-time employment. This finding is quite plausible in light of the findings on wages (Fitzenberger/Wunderlich, 2000). The wage growth of low skilled full-time employed females was the largest of all female full-timers, and in the case of part-timers wage growth in the lower part of the wage distribution was remarkably strong. Thus, the evidence is consistent with a labor demand interpretation where high wage gains for low skilled females (possibly due to institutional efforts in wage setting to reduce the gender wage gap) caused a decline in employment in the presence of a strong skill bias in labor demand.

In both countries, pure life-cycle employment profiles are in general very similar (see figures 4 and 5). We have tested several specifications of the profiles but age polynomials of second order fitted best for part-time employment and age polynomials of third order for full-time employment. Note that for high skilled females, the life-cycle profiles start at age 25, because of the longer duration of schooling in this case. In the following, we describe the pure life-cycle profiles which have been tested to exhibit a shape which is separable from time and cohort effects. Significant cohort and time effects, which are additively linked in our estimation equation, could shift the location of these profiles over time/cohort succession.

Regarding life-cycle profiles, full-time employment of high skilled females in the UK is again an exception (see figure 4). Their pure full-time life-cycle profile decreases between labor market entry at age 25 and age 45 by more than 60 ppoints while their part-time profile increases over the same age range by 40 ppoints. The full-time profile has the form of permanent exit and the part-time profile is inverse U-shaped. The loss of full-time employment of high skilled British females during the family phase is the strongest full-time employment loss over age of all country-skill combinations we investigate. In contrast to the full-time profile, the part-time profile does not differ very much from those of the other groups. Nevertheless, because of the strong time trend for full-time employed high skilled British females, amounting to 35 ppoints, the life-cycle profile has changed its location considerably over time, in contrast to medium and low skilled full-time employed females in the UK.

Because of the strong changes for high skilled females in the UK over the observation period the full-time employment rates of 25 to 35 years old females in 1975 for this group did not actually show such a strong permanent decline over the sample period of 20 years as suggested by the pure life-cycle profile. The latter effect was partly compensated by the strong positive time trend such that these cohorts actually experienced a return pattern during the sample period. British medium skilled females have a similar pattern of full-time employment over the life-cycle as high skilled females, but the decrease between labor market entry (at age 20 for this skill group) amounts only to 30 ppoints. The curve has also the shape of permanent exit, even though one 
finds a small increase of 5 ppoints between age 40 and age 50. The smallest variation in aggregate full-time employment rates over the life-cycle in Britain is observable for low skilled women. The rate decreases by 20 ppoints until age 35 and recovers then by roughly 10 ppoints with a local maximum at age 50. Part-time rates of low skilled women reach a maximum of 40 ppoints at age 45 . In contrast to high skilled females, there is no positive time trend which would compensate partly the decline in full-time employment rates over the life-cycle among low- and medium skilled females.

As mentioned before, Germany exhibits very similar shapes of the life-cycle profiles, but here we find differences across skill groups in full-time employment rates. The life-cycle full-time profile of German high skilled women exhibits a loss of 20 ppoints between age 25 and 35, a constant phase until age 50, and a further decline afterwards. Part-time rates, in contrast, peak at 20 ppoints at age 50 to stay constant until labor market exit at age 60. German medium skilled females are very similar to the British high skilled. The full-time life-cycle profile is very much the same but the employment loss is not so severe amounting to 50 ppoints at age 45 . After this age the rate decreases further. The profile increases at the right hand side over time due to the positive time trend. The part-time profile reaches its maximum at age 50 with 40 ppoints. In contrast, the low skilled women show a very flat full-time profile, which decreases from age 20 to age 30 by 20 ppoints and which remains nearly constant further onwards. Their part-time life-cycle profile is very much the same as for the high skilled. It peaks at age 45 with 20 ppoints and exhibits a small decline at the end of the age range.

In non of the six country-skill combinations analyzed here, the pure life-cycle profiles imply a complete return of the aggregate full-time employment rates to the pre family phase level. Depending on the observed group, full-time loss amounts to between roughly 10 and 60 ppoints. The weakest tendency to leave full-time employment during the life-cycle is observable for British and German low skilled females with the strongest tendency to return to full-time employment for British low skilled females. In contrast, gains in part-time employment vary between 20 and 40 ppoints. The countries do not differ very much in this respect. Part-time maxima during the life-cycle profiles seem to be marginally higher in Britain.

The picture emerging from the cohort profiles is that labor market behavior of females has changed in both countries across cohorts albeit in a slightly different manner. In general, cohorts born before 1955/56 (for the high skilled 1950/51), who entered the labor market before 1975 (1976) tend to have lower full-time rates and higher parttime rates. These changes are in a range of $+/-10$ ppoints. The broad trends are fairly similar but, nevertheless, the skill groups differ across countries. In the UK, older cohorts of high skilled full-time employed females exhibit lower full-time rates than younger cohorts. Medium and low skilled British full-time females experience no change across cohorts. For German full-timers a similar picture emerges. Here we find a lower full-time rate of high and medium skilled older full-timers. For low skilled full-timers the cohort effect of the pre 1975/76 entry cohorts is inverse U-shaped, it is positive for the older and negative for the younger pre 1975/76 entry cohorts. With regard to part-time employment, we find only a very weak cohort effect for low skilled British females. Cohorts born before 1955 have a marginally higher part-time rate. In contrast this applies more or less to all skill groups of German part-timers. As already mentioned, the size of the cohort effects is not very large, but they are significant. 


\section{Conclusions}

Rising female employment rates are ubiquitous in the industrialized countries. Despite this general trend, there are differences across countries in the experiences of specific groups of women and in the trends of full-time and part-time work. The widely accepted hypothesis of a skill bias in labor demand suggests differences across skill groups. Institutional differences in wage setting and in the social efforts to promote female employment may affect various groups in a different way. Changes in the sociological role model of women could vary across countries, in particular regarding the timing of these changes. Therefore, it is important to take account of differences across birth cohorts.

Taking a cohort perspective, this paper provides an empirical analysis of trends in female employment rates both for West Germany and the UK. Based on large representative cross-sectional data from the mid 70's to the mid 90's, we distinguish three skill groups and we analyze full- and part-time employment separately. Applying the framework suggested by MaCurdy and Mroz (1995), we address the identification issue between cohort, age, and time effect. The test results imply a separable specification of these variables thus allowing to distinguish a life-cycle profile and a time trend which are both common to all cohorts.

The empirical results show many similarities but also some remarkable differences between West Germany and the UK regarding trends in full- and part-time work across skill groups. Over the life-cycle, full-time employment rates decrease strongly and part-time employment rates increase strongly in both countries. Thus, to a large extent women exit full-time employment during the family formation phase and for the most part they work part-time at a later age. The strength of this life-cycle effect differs between skill groups and between the two countries. In Germany it is strongest for the medium skilled women and in the UK for the high skilled. Also the time trends differ considerably. While full-time employment rates increase strongly over time for the medium skilled in Germany and the high skilled in the UK, they even decline for the low skilled in Germany. Thus, the small increase in the full-time employment rates both in Germany and the UK is the result of various strong counteracting effects. The decline in full-time employment among low skilled females over time in Germany is counteracted by the decline in the share of low skilled females and the increase in fulltime employment among medium skilled employment. The strong increase in full-time employment among high skilled women in the UK and the increase in their share of the female labor force is counteracted by the demographics of an aging society together with negatively sloped life-cycle profiles. The latter effect is also relevant for Germany. Somewhat surprisingly the time trends in part-time employment rates did only show a slight increase for low skilled females in Germany. For the other groups in Germany and for the medium skilled in the UK we find no time trend at all. The low and high skilled in the UK exhibit even a decline in part-time rates over time albeit the change is very small for the low skilled. Thus, the strong aggregate increase in part-time rates is mainly due to the demographic aging effect together with increasing life-cycle profiles and to skill upgrading in both countries since medium skilled women in Germany and both medium and high skilled women in the UK exhibit somewhat higher part-time rates compared to low skilled women. 
Taken together our results show strong differences across countries and skill groups and there is in fact some evidence of a "myth of rising female employment" since the rise in employment rates is concentrated in part-time employment and, most importantly, it is mainly due to composition effects. Further research should attempt to link our findings more closely to the evolution of the wage structure and the cross country differences in wage setting. 


\section{References}

Altonji, J. and R. Blank (1999) Race and Gender in the Labor Market. In: Ashenfelter, O. and Card, D. (Hrsg.), Handbook of Labor Economics, Vol. III, pp. 3144-3259.

Berman, E., J. Bound and S. Machin (1998) Implications of Skill-Biased Technological Change : International Evidence. The Quarterly Journal of Economics, 113, pp.1245-1279.

Black, B., M. Trainor, and J. E. Spencer (1999) Wage protection systems, segregation and gender pay inequalities: West Germany, the Netherlands and Great Britain. Cambridge Journal of Economics, 23, 449-464.

Blau, F. and Kahn, L. (1997) Swimming Upstream: Trends in the Gender Wage Differential in the 1980s. Journal of Labor Economics, 15, pp.1-42.

Blossfeld, H.-P. and G. Rohwer (1997) Part-Time Work in West Germany. In: Blossfeld, H.-P. and C. Hakim (eds.) Between Equalization and Marginalization. Women Working Part-Time in Europe and the United States of America. Oxford: Oxford University Press, pp.164-190.

Blossfeld, H.-P. and C. Hakim (eds.) (1997) Between Equalization and Marginalization. Women Working Part-Time in Europe and the United States of America. Oxford: Oxford University Press.

Blundell, R. and T. MaCurdy (1999) Labour Supply: A Review of Alternative Approaches. In: O. Ashenfelter (ed.) Handbook of Labor Economics, Volume $3 \mathrm{~A}$.

Burchell, B. J., A. Dale, and H. Joshi (1997) Part-time Work among British Women. In: Blossfeld, H.-P. and C. Hakim (eds.) Between Equalization and Marginalization. Women Working Part-Time in Europe and the United States of America. Oxford: Oxford University Press, pp.210-246.

Fitzenberger, B., (1998) The Moving Blocks Bootstrap and Robust Inference for Linear Least Squares and Quantile Regressions. Journal of Econometrics, 82, pp. $235-287$.

Fitzenberger, B., R. Hujer, T.E. MaCurdy, and R. Schnabel (2001) Testing for Uniform Wage Trends in West Germany: A Cohort Analysis using Quantile Regressions for Censored Data. Empirical Economics, pp. 41-87.

Fitzenberger, B., Schnabel, R., and Wunderlich, G. (2001) The Gender Gap in Labor Market Participation and Employment: A Cohort Analysis for West Germany. Discussion Paper 01-47, Centre for European Economic Research (ZEW), Mannheim.

Fitzenberger, B. and Wunderlich, G. (2000) Gender Wage Differences in West Germany: A Cohort Analysis. Discussion Paper 00-48, Centre for European Economic Research (ZEW), Mannheim. 
Fitzenberger, B. and Wunderlich, G. (2001) The Changing Gender Gap Across the Wage Distribution in the U.K. Discussion Paper 01-56, Centre for European Economic Research (ZEW), Mannheim.

Franz, W. (1999) Arbeitsmarktökonomik. 4th ed. Berlin, Heidelberg, and New York: Springer.

Giles, Ch., A. Gosling, F. Laisney, and T. Geib (1998) The Distribution of Income and Wages in the UK and West Germany 1984-1992. London: IFS.

Goldin, C. (1990) Understanding the Gender Gap. An Economic History of American Women. New York, Oxford: Oxford University Press, Chapter 5: The Changing Economic Role of Married Women. pp. 119-158.

Hakim, C. (1993) The Myth of Rising Female Employment. Work, Employment and Society, Vol. 7, pp. 97-120.

Jacobsen, J. P. (1998) Labor Force Participation: Analysis of Trends. In: J.P. Jacobsen, The Economics of Gender. 2nd ed., Oxford: Blackwell, Chapter 4, pp. 106-153.

MaCurdy, T. E. and T. Mroz (1995) Measuring Macroeconomic Shifts in Wages from Cohort Specifications. Unpublished Manuscript, Stanford University and University of North Carolina.

OECD (1988) Employment outlook. Paris: OECD.

OECD (1996) Employment outlook. Paris: OECD.

OECD (1997) Education at a glance. OECD Indicators. Paris: OECD. Chapter E: Social and labour market outcomes of education. pp. 239-276.

Rubery, J., M. Smith and C. Fagan (1999) Women's Employment in Europe. Trends and Prospects. London and New York: Routledge.

Shapiro, D. and F. L. Mott (1994) Long-Term Employment and Earnings of Women in Relation to Employment Behavior Surrounding the First Birth. The Journal of Human Resources. Vol. 24, pp. 249-275.

Shaw, K. (1994) The Persistence of Female Labor Supply. Journal of Human Resources, Vol. 24, pp. 348-378.

Stephens, M. and J. Ward-Batts (2001) The Intra-Household Allocation of Assets: Evidence from the Separate Taxation of Spouses in the UK. Unpublished manuscript, University of Michigan.

Vermeulen, H., S. Dex, and B. Callan (1995) Tax Systems and Married Women's Labour Force Participation: A Seven Country Comparison. ESRC working paper 95-8, University of Essex. 


\section{A Appendix}

\section{A.1 Methodological Details of the Empirical Approach}

The goal of the empirical analysis is to analyze trends both in the part-time and the full-time employment rates of women in West Germany and the UK by skill group. Let $E R$ denote the full-time or the part-time employment rate. We investigate movements in $E R$ for synthetic cohorts over time. Testing for uniformity across cohorts allows to investigate whether $E R$ moves uniformly over time. Alternatively, it could be the case that $E R$ trends differ across cohorts, which would then indicate the presence of "cohort effects". Under certain conditions, which will be discussed later, a cohort effect designates a movement of the entire life-cycle $E R$ profile for a given cohort relative to other cohorts. In providing a parsimonious representation, we are able to pin down precisely the differences in $E R$ trends across groups of workers defined by skill level. We also explicitly take into account the possibility that $E R$ is sensitive to cyclical effects.

\section{A.1.1 Characterizing Profiles of Full-time or Part-time Employment Rates}

We denote the age of a person by $\alpha$ and the calendar time by $t$. A cohort $c$ can be defined by the year of birth. The variables age, cohort, and calendar year are linked by the relation $t=c+\alpha$. Often researchers investigate empirically the cross-sectional relation between age and $E R$ in a given year and trends in this relationship over time:

$$
E R(t, \alpha)=f(t, \alpha)+u \quad .
$$

The deterministic function $f$ measures the systematic variation in $E R$, and $u$ reflects cyclical or transitory phenomena. Movements of $f$ as a function of $t$ describe how crosssection age profiles in $E R$ shift over time. The cross-sectional relation $f$ as a function of age does not describe the "life-cycle" profile for any cohort, or, put differently, the cross-section relation may very well be the result of "cohort effects". Profiles in ER can also be expressed as a function of cohort and age

$$
g(c, \alpha) \equiv g(t-\alpha, \alpha) \equiv f(t, \alpha)
$$

where the deterministic function $g$ describes how age- $E R$ profiles differ across cohorts. Holding age constant, $g(c, \alpha)$ describes $E R$ for different cohorts over time. Holding the cohort constant yields the profile experienced by a specific cohort over time and age. The latter can be interpreted as the actual $E R$ profile, because it reflects the movements of $E R$ over the actual life-cycle for a given cohort.

The different parameterizations $g(c, \alpha)$ and $f(t, \alpha)$ are equivalent representations of the same relationship. Without further assumptions, "pure life-cycle effects" due to 
aging or "pure cohort effects" cannot be identified. Because of our focus on $E R$ trends for a given cohort over time, we use the cohort representation in equation (7) as the perspective of our analysis.

\section{A.1.2 Testing for Uniform Changes over Time}

Our analysis investigates whether time trends in $E R$ are uniform across cohorts, in the sense, that every cohort experiences the same time trend and the same age related change. The latter is interpreted here as the life-cycle effect (三 "pure age effect"). Despite the identification issues discussed above, the existence of a uniform time trend across cohorts is a testable implication in the framework presented here. If such a uniform time trend is found, it is designated as the macroeconomic trend for the group considered. ${ }^{5}$ However, as can be seen from the empirical results, the uniform time trends found differ by country, skill level, and employment status.

Two notions of changes over time prove useful: First, changes for a given cohort in the labor market over time ("Insider trend"), and second, changes over time experienced by successive cohorts when entering the labor market ("Entry trend"). The Insider trend is given by

$$
\left.\frac{\partial g}{\partial t}\right|_{c}=\left.\frac{\partial g}{\partial \alpha}\right|_{c} \equiv g_{\alpha}(c, \alpha) \equiv g_{\alpha}
$$

resulting from the simultaneous change of time and age. Alternatively, holding age constant yields the change observed over different cohorts at a given age. For the age at labor market entry, $\alpha_{e}$, the Entry trend is given by

$$
\left.\frac{\partial g}{\partial t}\right|_{\alpha=\alpha_{e}}=\left.\frac{\partial g}{\partial c}\right|_{\alpha=\alpha_{e}} \equiv g_{c}\left(c, \alpha_{e}\right)=g_{c}\left(t-\alpha_{e}, \alpha_{e}\right) \equiv e(t)
$$

Again, this results from two effects, a change of cohort and time.

Now, two testable separability conditions arise. If the changes over time can be characterized as the sum of a pure aging effect and a pure time effect in the following way

$$
g_{\alpha}=a(\alpha)+b(t)=a(\alpha)+b(c+\alpha),
$$

then the life-cycle effect is independent of the calendar year $t$. This condition is designated as the "uniform Insider trend hypothesis", which we denote by $H_{U I}$. It implies that each cohort faces the same change in $E R$ over the life-cycle due to aging $a(\alpha)$ and that economy wide shifts $b(t)$ are common to all cohorts in the same year but they occur at different points during the life-cycle of each cohort. If the separability condition (10) holds, we can construct a "life-cycle profile" independent of the calendar

\footnotetext{
${ }^{5}$ If no uniform trend is found, the average across age groups combines age, time, and cohort effects.
} 
year and a macroeconomic time trend independent of age. Condition (10) is violated if interaction terms of $\alpha$ and $t$ enter the specification of $g_{\alpha}$.

Integrating back the derivative condition (10), with respect to $\alpha$, yields an additive form for the systematic component of the $E R$ profiles $g(c, \alpha)$ :

$$
g(c, \alpha)=G+K(c)+A(\alpha)+B(c+\alpha)
$$

where $G+K(c)$ is the cohort specific constant of integration. $H_{U I}$ can be tested by investigating whether "interaction terms" $R(\alpha, t)$ enter specification (11), which are constructed as integrals of interaction terms of $\alpha$ and $t$ in $g_{\alpha}$.

If, in addition to $H_{U I}$, the Entry trend equals the macroeconomic time trend

$$
e(t)=b(t)
$$

a stronger hypothesis can be formulated. We designate this hypothesis as the "Hypothesis of uniformity in the Insider trend and the Entry trend" and denote it as $H_{U}$. Under this hypothesis the life-cycle profile of each new labor market cohort is a parallel shift of the profile of the previous cohort corresponding to the uniform time trend $b(t)$ for all cohorts already in the labor market. Again, this is a testable implication. Given specification (11), condition (12) implies that $K(c)$ is equal to zero for the cohorts entering the labor market during the period of observation.

\section{A.1.3 Implementation of the Tests}

The hypothesis $H_{U I}$ requires equation (11) to hold against a more general alternative, whereas the (stronger) hypothesis $H_{U}$ additionally requires $K_{a 2}=0$ (no cohort effect after 1976). Formally, it is also possible to test the hypothesis that $K_{b 2}=0$ and $K_{b 3}=0$. This test of equation (12) for older cohorts is not directly based on the entry age, because these cohorts are only observed in the data during a later phase of their life-cycle.

In order to formulate a test of $H_{U I}$, we consider in the derivative $g_{\alpha}$ the interaction term $\alpha t$. The implied non-separable variant of $g(c, \alpha)$ expands (11) by incorporating the integral of this interaction term

$$
R=\int \alpha(c+\alpha) d \alpha=c \alpha^{2} / 2+\alpha^{3} / 3
$$

Consequently, the most general formulation of equation (11) also involves $R$ and the orthogonalized year dummies. The formal test of $H_{U I}$ is a test of whether or not $R$ is significant. The test of the stronger hypothesis $H_{U}$ is a test of whether or not both $R$ and $c a^{2}$ are significant. 
Only if the separability condition $H_{U I}$ holds, is it meaningful to construct an index of a life-cycle profile, as a function of pure aging $A(\alpha)$, and a linear macroeconomic trend index $B(t)$. Otherwise, a different $E R$ profile would apply for each cohort. As pointed out above, it is important to recognize that neither the level nor the coefficient on the linear term are identified for these indices in a strict econometric sense.

\section{A.1.4 Block Bootstrap Procedure for Inference}

In the context of this study, we allow for the error terms being dependent across individuals within cohort-year-cells and across adjacent cohort-year-cells. The dependence is assumed to take the form of rectangular $\mathrm{m}$-dependence across time and across cohorts. We use a flexible Block Bootstrap approach allowing for standard error estimates, which are robust against fairly arbitrary heteroskedasticity and autocorrelation of the error term (see Fitzenberger (1998) for this method in the time series context, Fitzenberger, Schnabel, and Wunderlich (2001), and Fitzenberger and Wunderlich $(2000,2001)$ for applications). The Block Bootstrap approach employed here extends the standard bootstrap procedure in that it draws blocks of observations to form the resamples. For each observation in a block, the entire vector comprising the endogenous variable and the regressors is used, i.e. we do not draw from the estimated residuals.

For Germany the empirical analysis is based on grouped data (cells) and we simply draw a two-dimensional block of observations with a block length of 10 in the cohort and 10 in the time dimension with replacement until the resample has become at least as large as the resample size. For the UK, the analysis is based on individual data but we allow for the same type of correlation structure across cells. To implement the block bootstrap approach based on individual data, we draw blocks of entire cells (i.e. all individual observations within a cell) to form the resample.

According to our block bootstrap approach, standard error estimation takes account of error correlation both within a cohort-year-cell and across pairs of cohorts and time periods which are at most 9 years in the cohort dimension and 9 years in the time dimension apart. In the absence of a clear cut decision rule about the choice of blocksize, we experimented somewhat with slightly smaller and larger blocks without causing changes in the substance of the results. 


\section{A.2 Figures and Tables}

Table 1: Parameter Estimates of Full-time and Part-time Employment Rates for British Females for Skill Groups U (Low Skilled), M (Medium Skilled), and H (High Skilled).

\begin{tabular}{|c|ccc|ccc|}
\hline Groups & \multicolumn{3}{|c|}{ Full-time } & \multicolumn{3}{c|}{ Part-time } \\
\hline Skill Level & $U$ & $M$ & $H$ & $U$ & $M$ & $H$ \\
\hline Intercept & .338 & .504 & .695 & .087 & .161 & .196 \\
& $(.042)$ & $(.039)$ & $(.084)$ & $(.027)$ & $(.048)$ & $(.044)$ \\
\hline$\alpha$ & -.346 & -.523 & -.942 & .318 & .258 & .334 \\
& $(.062)$ & $(.063)$ & $(.119)$ & $(.014)$ & $(.022)$ & $(.033)$ \\
\hline$\alpha^{2}$ & .213 & .271 & .444 & -.063 & -.057 & -.074 \\
& $(.031)$ & $(.037)$ & $(.059)$ & $(.004)$ & $(.005)$ & $(.007)$ \\
\hline$\alpha^{3}$ & -.035 & -.041 & -.068 & & & \\
& $(.004)$ & $(.006)$ & $(.009)$ & & & \\
\hline$t$ & & & .574 & .258 & & -.301 \\
& & & $(.279)$ & $(.175)$ & & $(.264)$ \\
\hline$t^{2}$ & & & -1.536 & -.992 & & .977 \\
& & & $(.893)$ & $(.559)$ & $(.844)$ \\
\hline$t^{3}$ & & & 2.089 & 1.198 & & -1.313 \\
& & & $(1.180)$ & $(.745)$ & $(1.117)$ \\
\hline$t^{4}$ & & & -1.148 & -0.597 & & 0.725 \\
& & & $(.673)$ & $(.428)$ & $(.638)$ \\
\hline$t^{5}$ & & & .219 & .105 & & -.141 \\
& & & $(.138)$ & $(.088)$ & $(.130)$ \\
\hline$c_{b}^{2}$ & & & .031 & -.007 & \\
& & & $(.011)$ & $(.003)$ & \\
\hline$c_{b}^{3}$ & & & & & & \\
& & & & & & \\
\hline$c_{a}^{2}$ & & & & & & \\
& & & & & & \\
\hline
\end{tabular}

Remark: We report the final preferred specification as the result of the tests. Empty cells imply that the respective coefficients are set to zero. The estimate of the covariance matrix is obtained using a Block Bootstrap Procedure (1000 resamples for skill groups (U) and (M) and (H)). Standard errors are found in parentheses. All specifications include year dummies which are orthogonalized with respect to the estimated time trend $B(t)$, i.e. the coefficients for the year dummies are restricted to be uncorrelated to the powers of $t$ in $B(t)$. 
Table 2: Parameter Estimates of Full-time and Part-time Employment Rates for German Females for Skill Groups U (Low Skilled), M (Medium Skilled), and H (High Skilled).

\begin{tabular}{|c|ccc|ccc|}
\hline Groups & \multicolumn{3}{|c|}{ Full-time } & \multicolumn{3}{c|}{ Part-time } \\
\hline Skill Level & $U$ & $M$ & $H$ & $U$ & $M$ & $H$ \\
\hline \hline Intercept & .582 & .073 & .066 & .021 & .012 & .125 \\
& $(.028)$ & $(.019)$ & $(.026)$ & $(.007)$ & $(.010)$ & $(.015)$ \\
\hline$\alpha$ & -.048 & -.620 & -.400 & .146 & .244 & .175 \\
& $(.074)$ & $(.036)$ & $(.048)$ & $(.007)$ & $(.012)$ & $(.017)$ \\
\hline$\alpha^{2}$ & .357 & .264 & .224 & -.029 & -.041 & -.034 \\
& $(.067)$ & $(.021)$ & $(.029)$ & $(.002)$ & $(.003)$ & $(.005)$ \\
\hline$\alpha^{3}$ & -.095 & -.038 & -.040 & & & \\
& $(.024)$ & $(.003)$ & $(.005)$ & & & \\
\hline$\alpha^{4}$ & .008 & & & & & \\
& $(.003)$ & & & & & \\
\hline$t$ & -.061 & .051 & & .025 & & \\
& $(.015)$ & $(.009)$ & & $(.005)$ & & \\
\hline$c_{b}^{2}$ & -.052 & .014 & .013 & -.005 & -.053 & -.077 \\
& $(.018)$ & $(.003)$ & $(.003)$ & $(.002)$ & $(.008)$ & $(.013)$ \\
\hline$c_{b}^{3}$ & -.011 & & & & -.009 & -.017 \\
& $(.005)$ & & & & $(.002)$ & $(.005)$ \\
\hline
\end{tabular}

Remark: Employment rates are defined as $f[p] r=f[p]$ emp/pop. We report the final preferred specification as the result of the tests. Empty cells imply that the respective coefficients are set to zero. The estimate of the covariance matrix is obtained using a Block Bootstrap Procedure (1000 resamples for skill groups $(\mathrm{U})$ and $(\mathrm{M})$ and $(\mathrm{H})$ ). Standard errors are found in parentheses. All specifications include year dummies which are orthogonalized with respect to the estimated time trend $B(t)$, i.e. the coefficients for the year dummies are restricted to be uncorrelated to the powers of $t$ in $B(t)$. 
Figure 1: Distribution of Skill Groups in Full-time and Part-time Employment for British and German Females aged 20-60 over time

Full-time Employment (Great Britain)

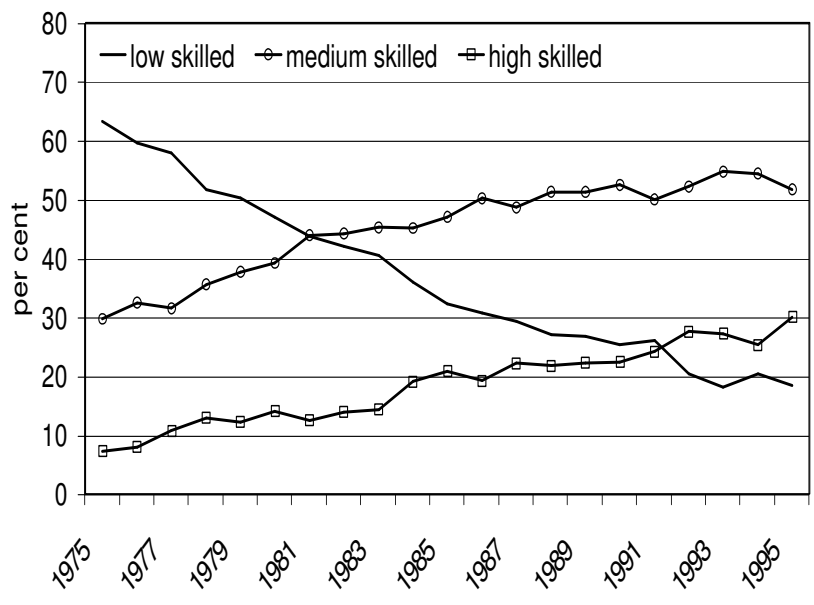

Part-time Employment (Great Britain)

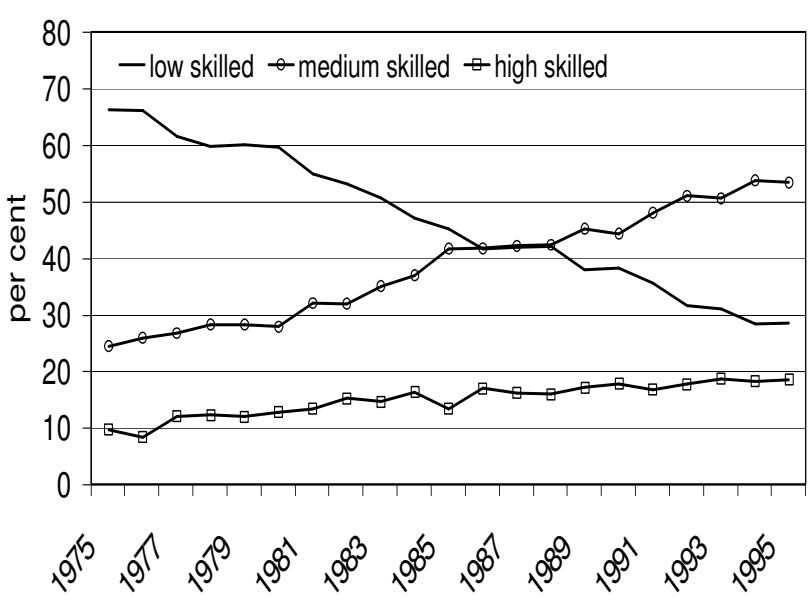

Full-time Employment (Germany West)

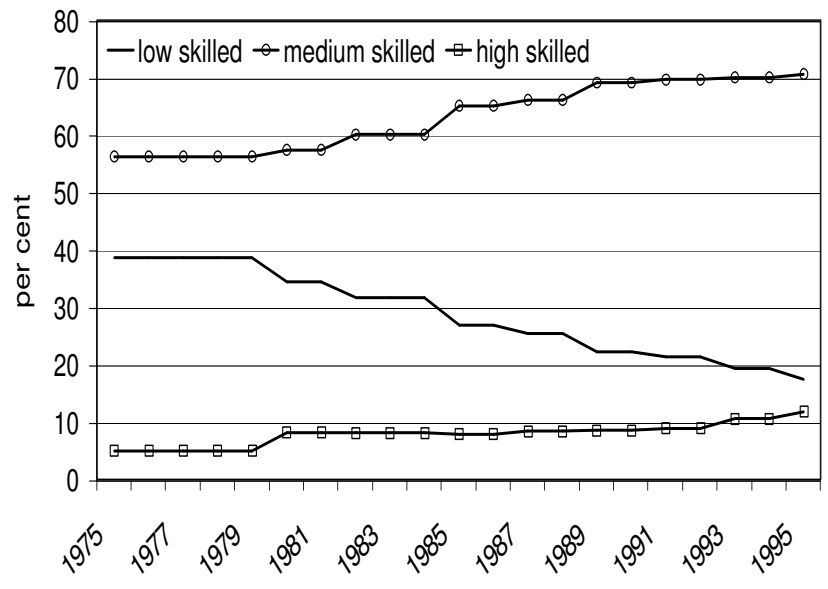

Part-time Employment (Germany West)

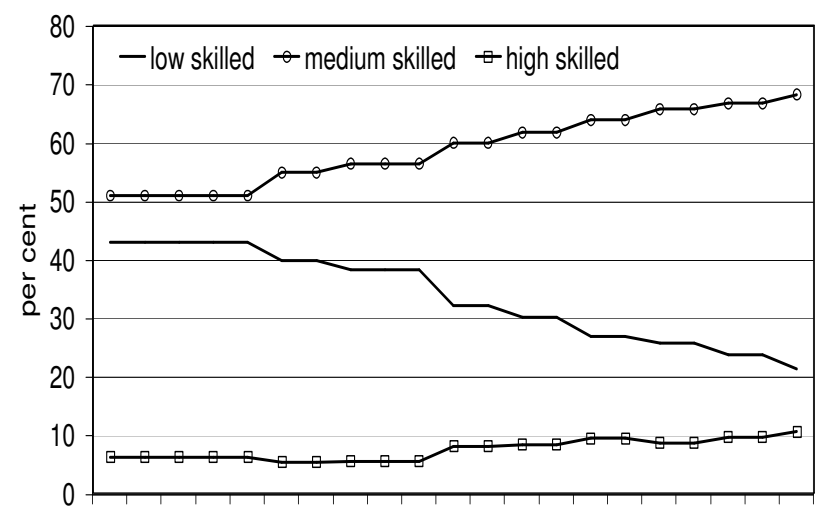

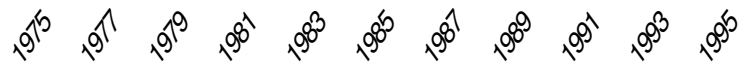


Figure 2: Cross Sections of Full-time Employment Rates by Age for British and German Females of Different Skill Level

Low skilled (Ger.)

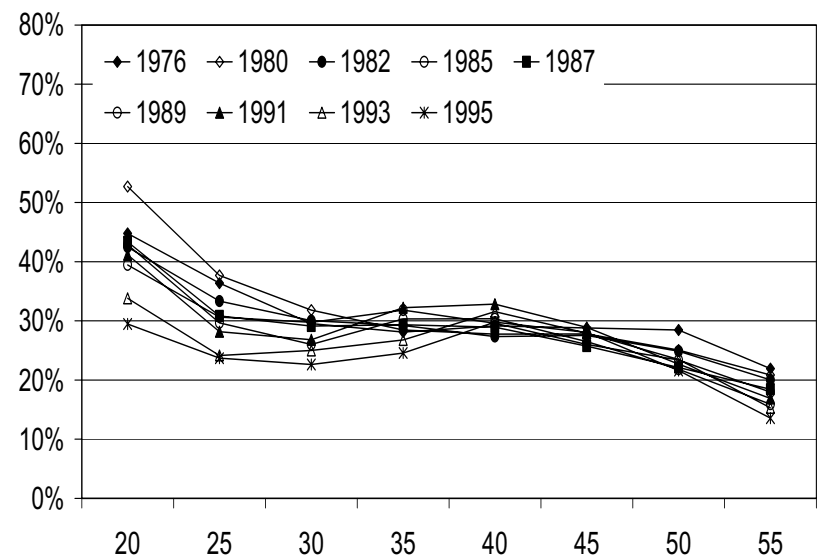

Medium skilled (Ger.)

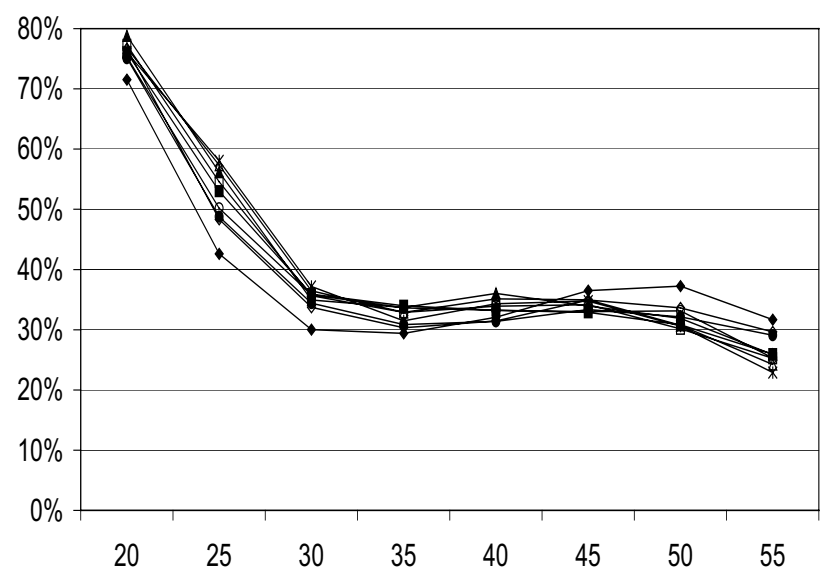

High skilled (Ger.)

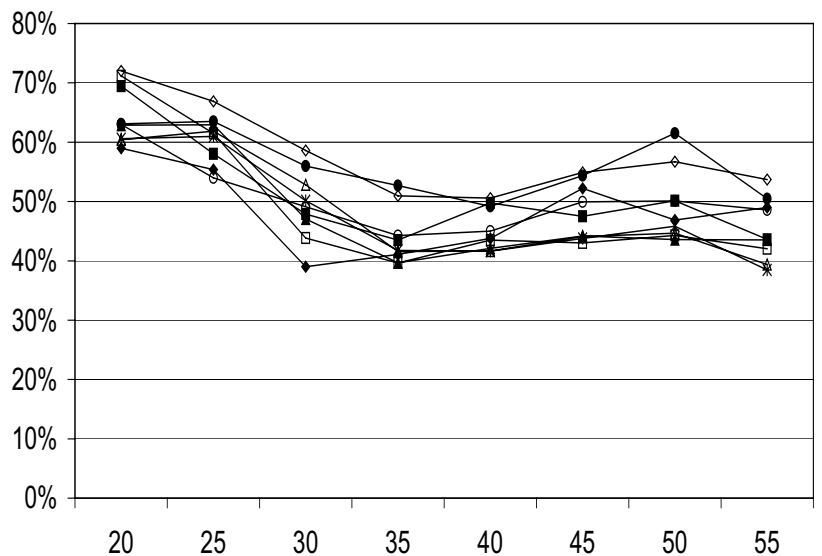

Low skilled (Brit.)

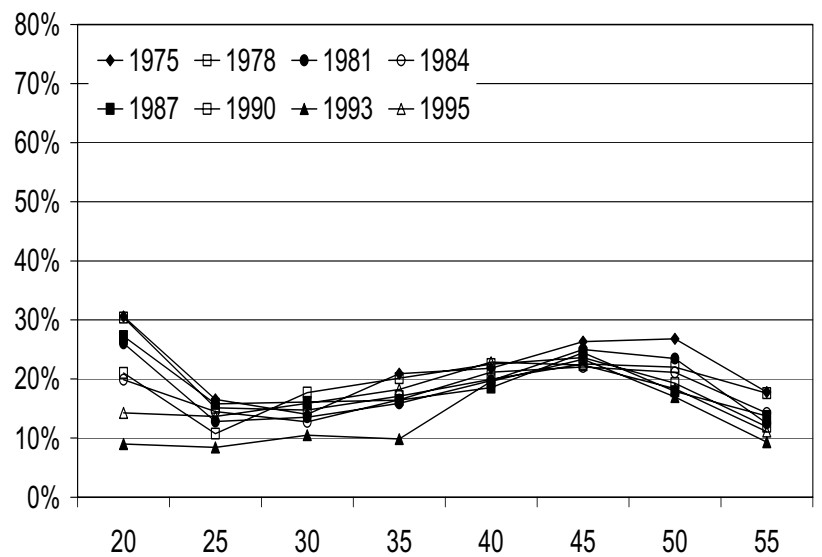

Medium skilled (Brit.)

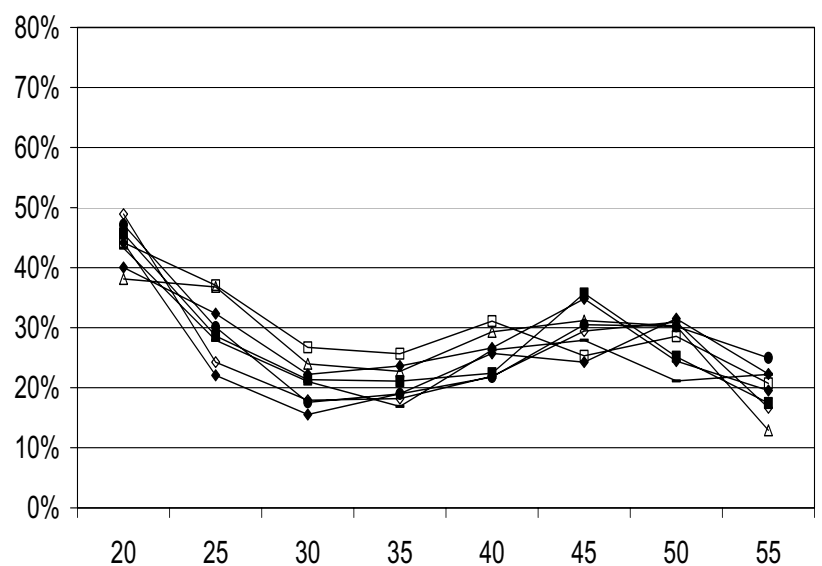

High skilled (Brit.)

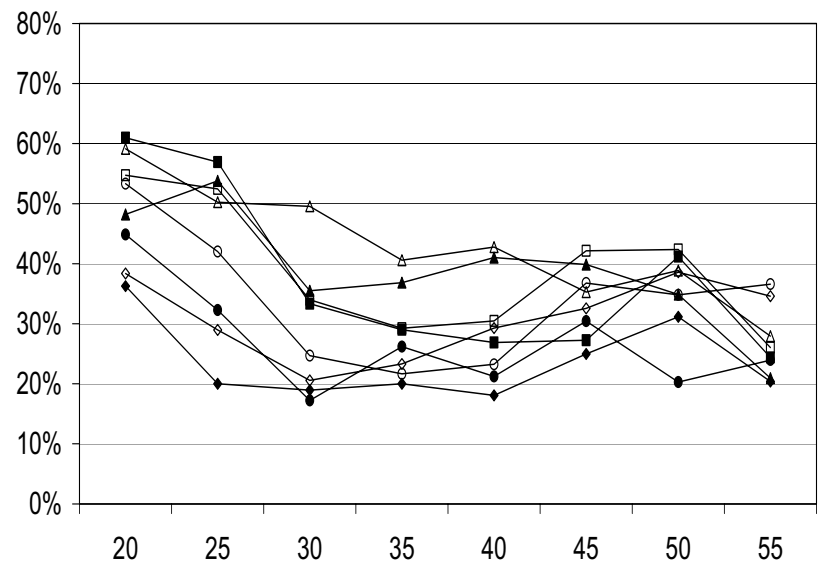


Figure 3: Cross Sections of Part-time Employment Rates by Age for British and German Females of Different Skill Level

\section{Low skilled (Ger.)}

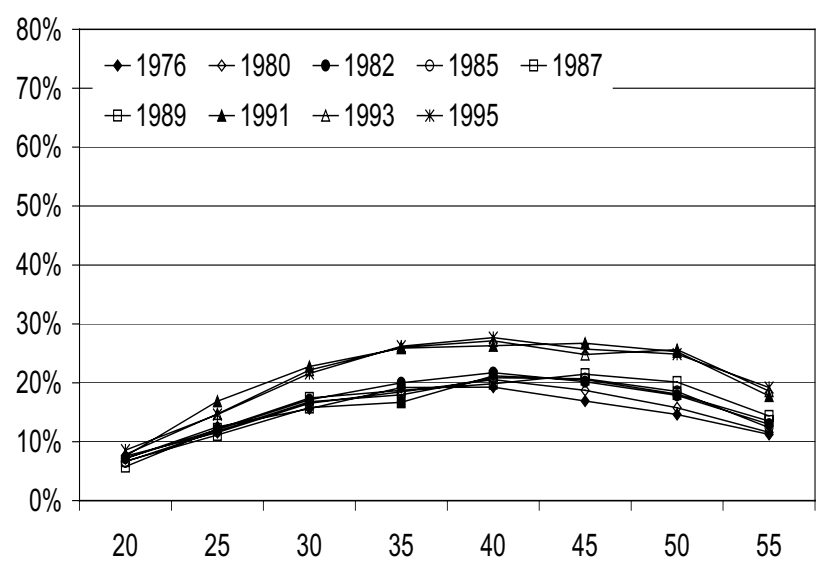

Medium skilled (Ger.)

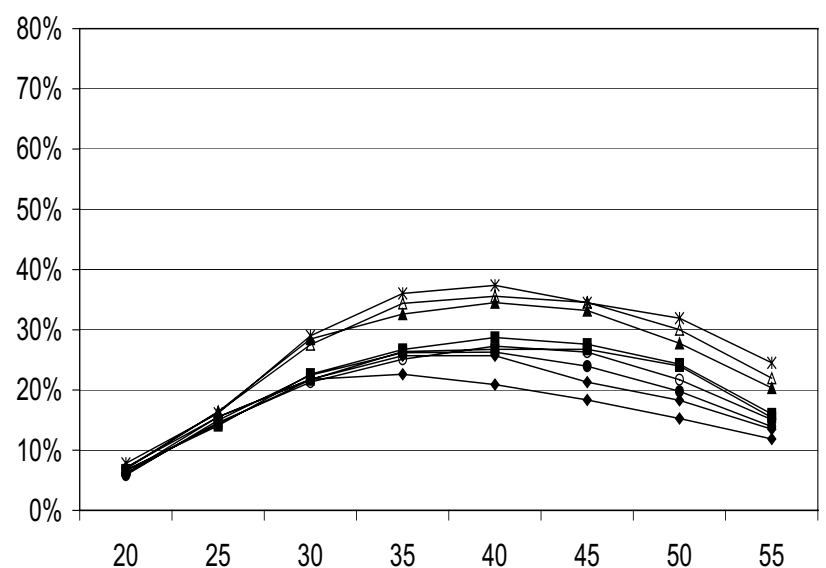

High skilled (Ger.)

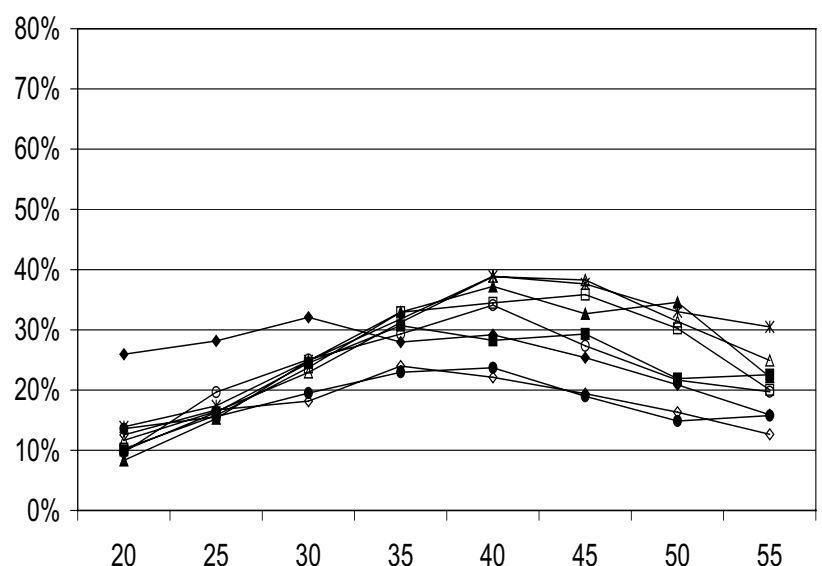

Low skilled (Brit.)

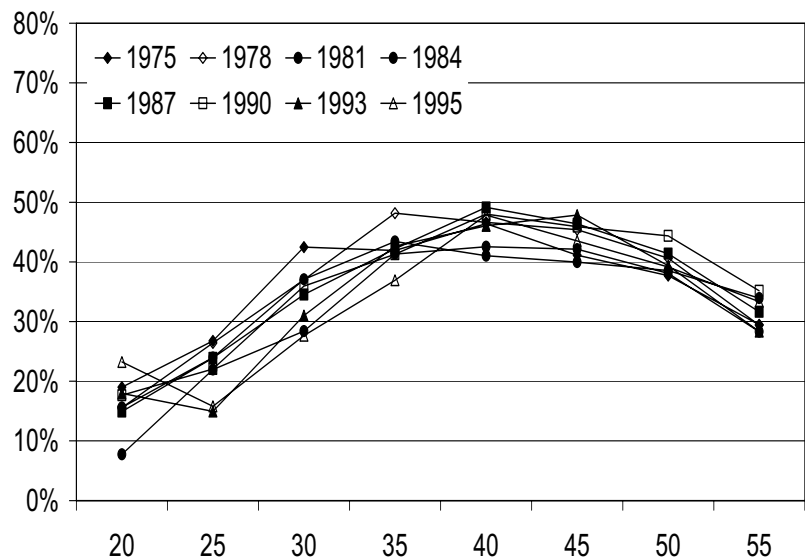

Medium skilled (Brit.)

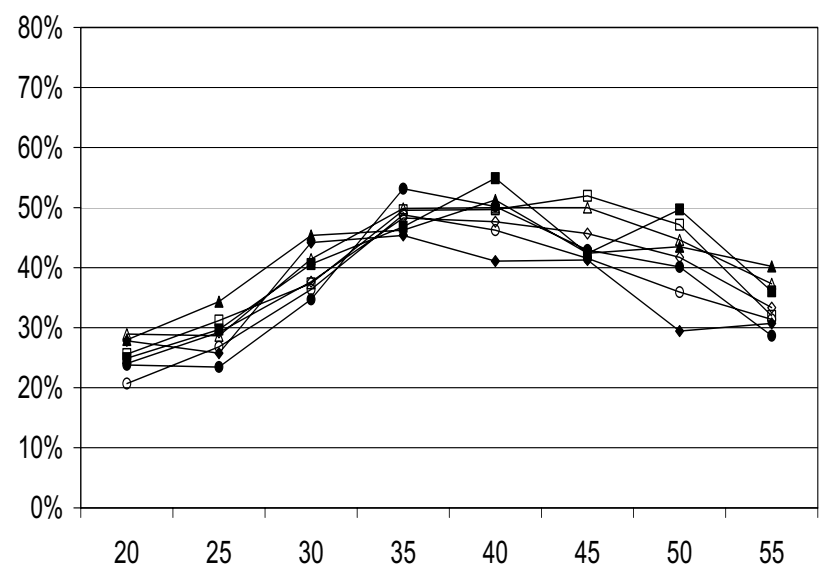

High skilled (Brit.)

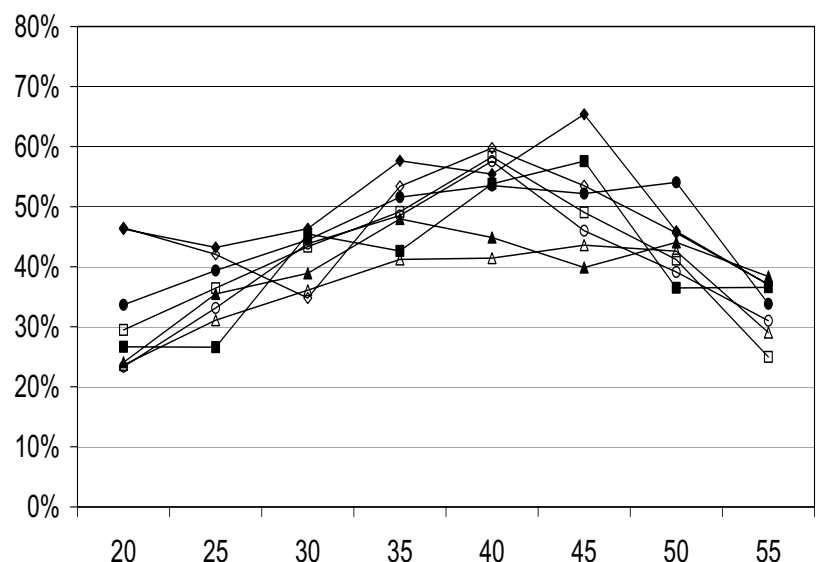


Figure 4: Full-time Employment Rates - Time Trends, Age Profiles, and Cohort Profiles for British and German Females for Skill Groups U (Low Skilled), M (Medium Skilled), and H (High Skilled). Based on Preferred Final Specifications.
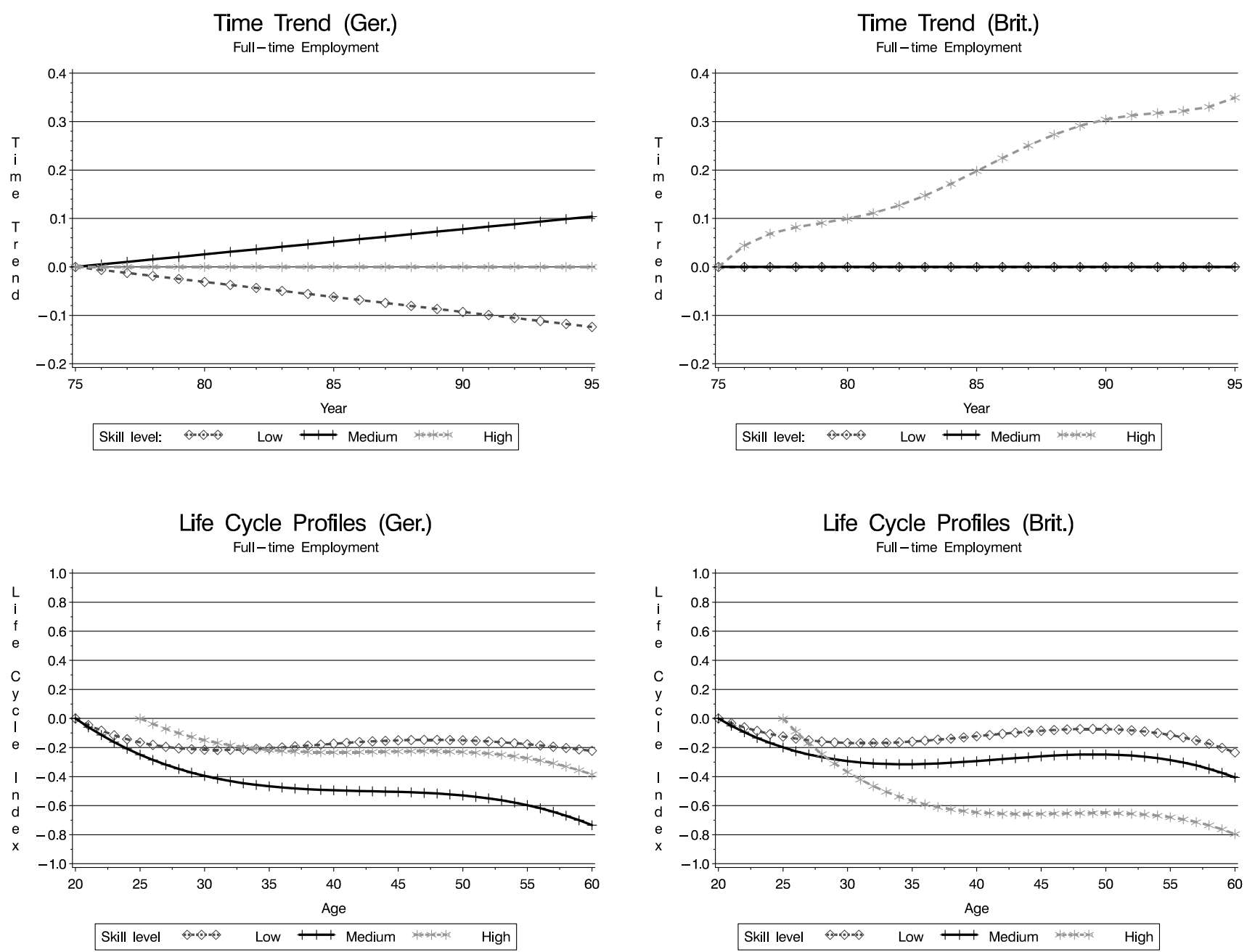

Cohort Profiles (Ger.)

Full-time Employment
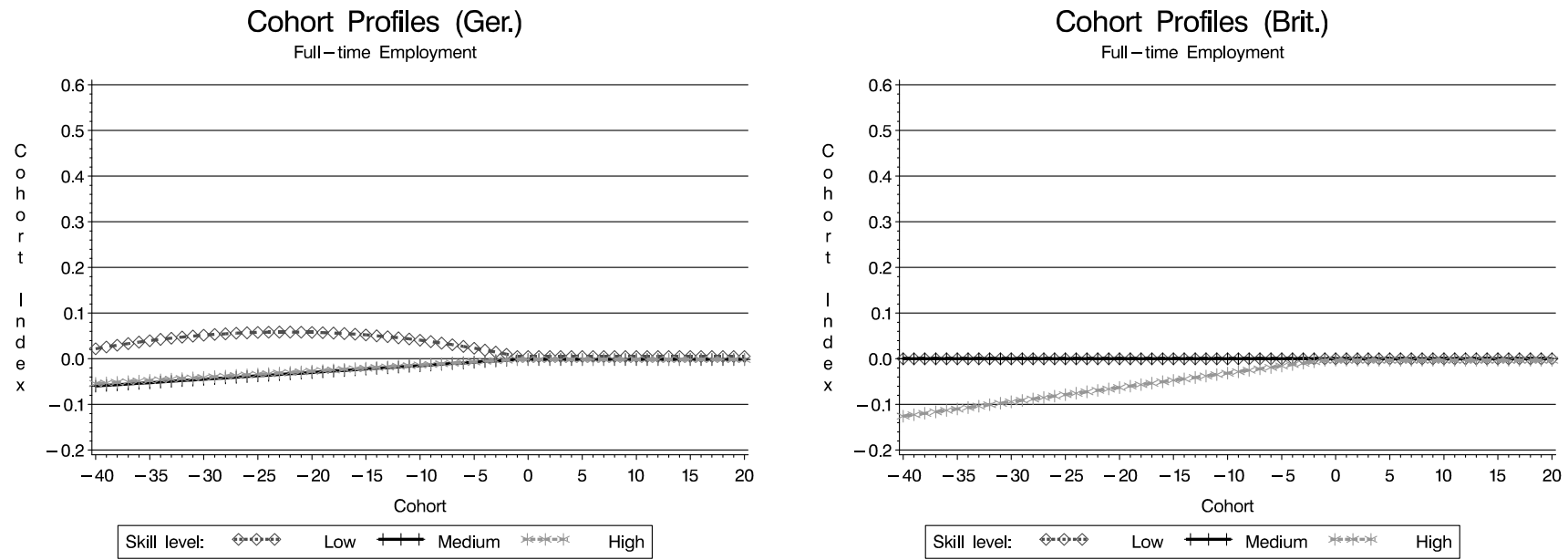
Figure 5: Part-time Employment Rates - Time Trends, Age Profiles, and Cohort Profiles for British and German Females for Skill Groups U (Low Skilled), M (Medium Skilled), and H (High Skilled). Based on Preferred Final Specifications.
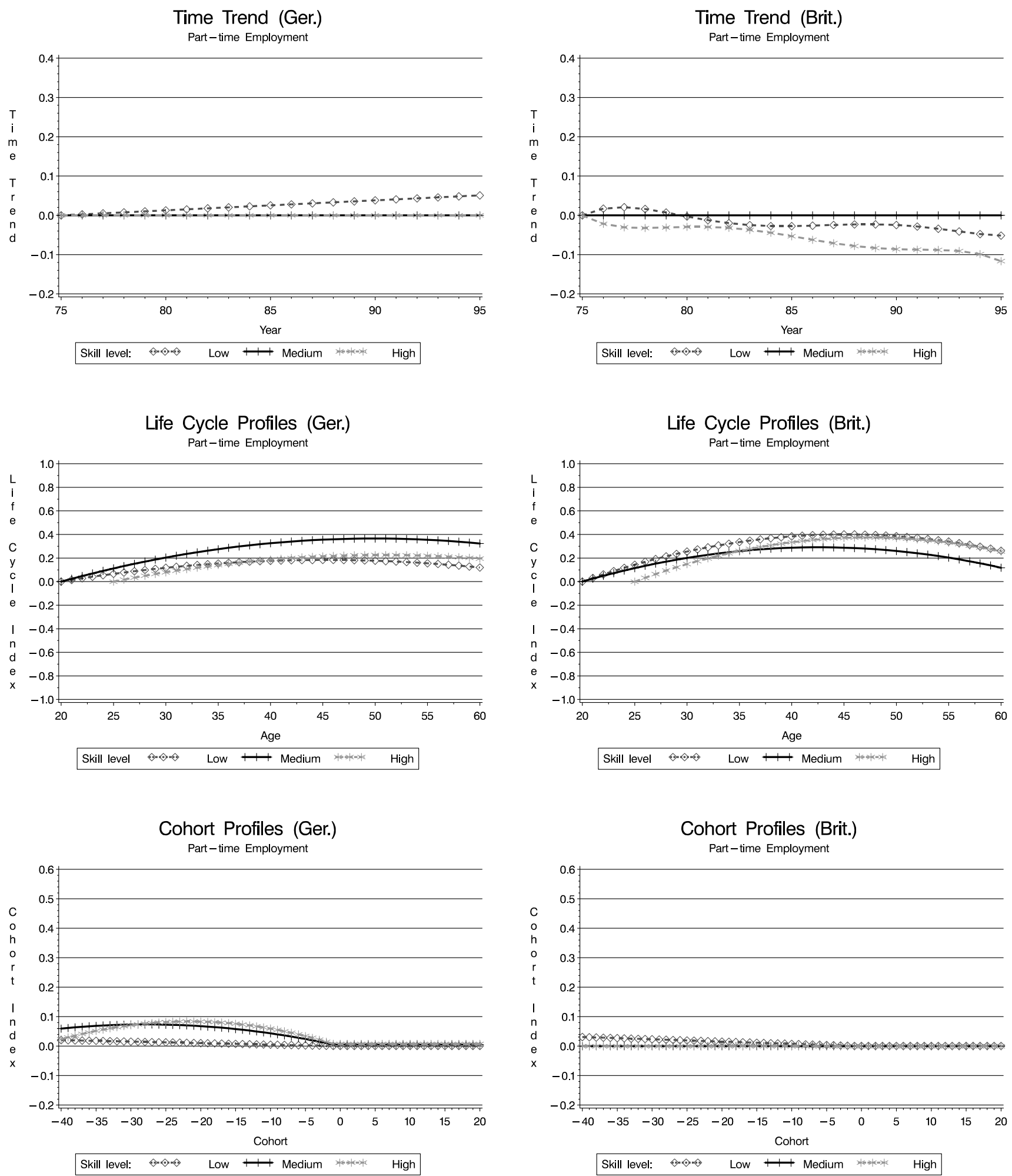